University of Nebraska - Lincoln

DigitalCommons@University of Nebraska - Lincoln

$12-2008$

\title{
Experiments and models for the thermal response of railroad tapered-roller bearings
}

\author{
Constantine M. Tarawneh \\ University of Texas-Pan American, tarawneh@utpa.edu \\ Kevin D. Cole \\ University of Nebraska-Lincoln, kcole1@unl.edu \\ Brent M. Wilson \\ University of Nebraska-Lincoln \\ Fadi Alnaimat \\ University of Texas-Pan American
}

Follow this and additional works at: https://digitalcommons.unl.edu/mechengfacpub

Part of the Mechanical Engineering Commons

Tarawneh, Constantine M.; Cole, Kevin D.; Wilson, Brent M.; and Alnaimat, Fadi, "Experiments and models for the thermal response of railroad tapered-roller bearings" (2008). Mechanical \& Materials Engineering Faculty Publications. 29.

https://digitalcommons.unl.edu/mechengfacpub/29

This Article is brought to you for free and open access by the Mechanical \& Materials Engineering, Department of at DigitalCommons@University of Nebraska - Lincoln. It has been accepted for inclusion in Mechanical \& Materials Engineering Faculty Publications by an authorized administrator of DigitalCommons@University of Nebraska Lincoln. 


\title{
Experiments and models for the thermal response of railroad tapered-roller bearings
}

\author{
Constantine M. Tarawneh, ${ }^{1}$ Kevin D. Cole, ${ }^{2}$ Brent M. Wilson, ${ }^{2}$ and Fadi Alnaimat ${ }^{1}$ \\ ${ }^{1}$ Department of Mechanical Engineering, The University of Texas-Pan American, Edinburg, TX 78539-2999, USA \\ ${ }^{2}$ Department of Mechanical Engineering, University of Nebraska-Lincoln, Lincoln, NE 68588-0656, USA \\ Corresponding author - C. M. Tarawneh, tel 956 381-2607; fax 956 381-3527, email tarawneh@utpa.edu
}

\begin{abstract}
The need to understand and quantify the heat transfer paths within tapered-roller bearings is of great importance in the railroad industry since bearing cup temperature measurement is the primary tool utilized in the removal of distressed bearings from service. Experiments were performed to acquire temperature histories at several locations on a stationary bearing subjected to heat sources imbedded in two rollers. The experimental results were compared to zero- and first-order thermal models to estimate overall heat transfer coefficients from the bearing. The results presented here can be used to explain some of the mechanisms that lead to overheating of tapered-roller bearings.
\end{abstract}

Keywords: bearing thermal response, heat transfer coefficient estimation, heat dissipation paths, bearing thermal models

\section{Introduction}

A primary reason for early removal of a railroad tapered-roller bearing from service is by setting off a track-side hot-bearing (hot-box) detector. A hot-box detector is designed to identify those bearings which are operating at temperatures greater than $105.5^{\circ} \mathrm{C}\left(190^{\circ} \mathrm{F}\right)$ above ambient conditions. As a safety precaution, train cars containing bearings which are determined to be running hot are removed from service for later disassembly and inspection of the bearings. Current technology has expanded the role of these detectors to monitor bearings that appear to "warm trend" relative to the average temperatures of the remainder of bearings on the train [1].

These early set-out bearings are often accompanied by distinct features which indicate that certain rollers are heating above normal temperatures. Bearings removed from service due to overheating usually contain discolored rollers in an otherwise normal bearing. The discoloration observed indicates that the rollers had seen temperatures greater than what is normal during operating conditions. This phenomenon has prompted a need to understand and quantify the heat transfer and dissipation paths within the bearing to determine if heat generated by the rollers can have a pronounced effect on bearing cup temperatures. Hence, initial work performed by the authors of this paper focused on determining conditions that would cause the discoloration observed in the rollers. A furnace was used to heat numerous rollers to elevated temperatures in various environments. Results indicated that the discoloration that best matched that observed in bearings removed from service were rollers heated in grease at temperatures over $232^{\circ} \mathrm{C}\left(450^{\circ} \mathrm{F}\right)$ for periods of at least $4 \mathrm{~h}$ [2].
Based on this initial work, several laboratory experiments were conducted using heaters embedded in two rollers to study the dynamics of heating in railroad tapered-roller bearings. This paper describes the results of these heat transfer experiments. The paper begins with a review of current detection methods and previous studies that investigated bearing heating due to the presence of defects. Next, the experimental setup and procedures are explained in detail, which is then followed by the development of zero- and first-order models that were used to fit the experimental data in order to estimate overall heat transfer coefficients for the bearing. The paper wraps up with a discussion of the results and a summary.

\section{Background and literature review}

Over the past few decades, scientists and experts have developed several techniques to detect bearing defects before the onset of failure, and numerous methods to predict the life of bearings. These techniques vary in the level of sophistication and range from simple methods [3] to more advanced techniques and stochastic prognostics [4] to full-scale reliability analysis [5] and run-to-failure lifetime testing [6]. Acoustic analysis, lubrication analysis, and temperature monitoring are the three most commonly used techniques. Acoustic analysis can detect any abnormalities within the bearing by examining the sound signals of each of its components [7]. Lubrication analysis can reveal the condition of the lubricant by the amount of contamination and degradation. Temperature monitoring does not reveal the actual condition of bearing components as accurately as acoustic or lubrication analysis, but is considered the simplest and fastest method of providing in- 


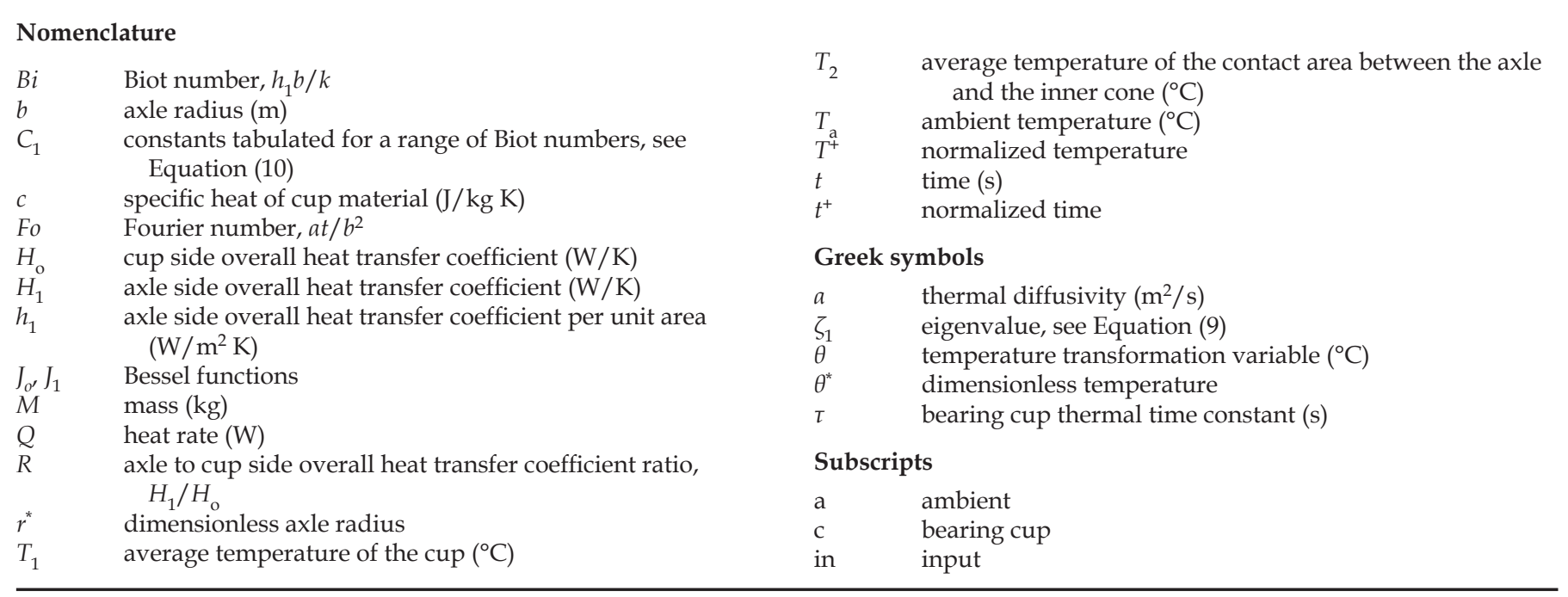

sight into potential bearing problems. Most recently, a new approach for the detection of localized bearing defects was proposed called matching pursuit, which is an improved vibration analysis. Matching pursuit takes into account the temporal, spectral, and the scale characteristics of the vibration produced by a defect to provide an easier way of signal reconstruction leading to a more flexible signature extraction. Hence, a high signal-to-noise ratio is achieved which facilitates the detection at the early stage of failure development [8].

There are several factors that can lead to premature bearing removal. A 2005 Amsted Rail inspection of bearings removed from service revealed that spalling was responsible for an estimated $26.5 \%$ of removals, water contamination accounted for $26 \%$ of removals, loose bearings contributed to $22.6 \%$ of removals, associated equipment caused approximately $10.5 \%$ of removals, and miscellaneous or other factors accounted for the remaining $14.4 \%$ of early bearing removals. An abnormal operating condition usually produces heat buildup within a bearing. The excessive heat tends to lower the viscosity of the lubricant, which reduces the thickness of the fluid film that separates the surfaces. As a consequence, metal-to-metal contact occurs which eventually leads to premature bearing failure. Refer to Figure 1 for a detailed component view of a typical railroad tapered-roller bearing.

Theoretical studies examined two abnormal operating conditions, a jammed roller bearing and a stuck brake situation
$[9,10]$. A partially jammed roller bearing is one that is rotating with velocities greater than zero but less than the epicyclic speed, whereas, a fully jammed roller bearing is one that has no velocity with respect to the cage. The theoretical studies revealed that the maximum temperature within the bearing assembly can reach $268^{\circ} \mathrm{C}$ for a jammed roller and $126^{\circ} \mathrm{C}$ for a stuck brake, compared to the normal operating condition temperature of $81^{\circ} \mathrm{C}$. In a similar study, a dynamic model of the torque and heat generation rate in tapered-roller bearings under excessive sliding conditions was developed using the program SHABERTH [11]. The investigation focused on jammed roller bearings, and the model was run with an assumed ambient temperature of $25^{\circ} \mathrm{C}\left(77^{\circ} \mathrm{F}\right)$, a load per row of $80,000 \mathrm{~N}$ $(18,000 \mathrm{lb})$ and a rotational speed of $560 \mathrm{rpm}$ which corresponds to a train speed of $97 \mathrm{~km} / \mathrm{h}(60 \mathrm{mph})$. The study concluded that the heat generated in the bearing was proportional to the number of jammed rollers and that the heat generation at the roller-end contacts increased with the number of jammed rollers. In yet another theoretical work, thermally-induced failures in railroad class $F\left(6 \frac{1}{2} \times 12\right)$ tapered-roller bearings observed in laboratory experiments when the bearings were operating at high speeds were modeled using finite element analysis with ABAQUS along with FORTRAN [12]. The experiments were conducted by the Association of American Railroads (AAR), and showed that new (defect-free) bearings failed after 200$300 \mathrm{~h}$ of operation at a speed of $161 \mathrm{~km} / \mathrm{h}(100 \mathrm{mph})$ and none

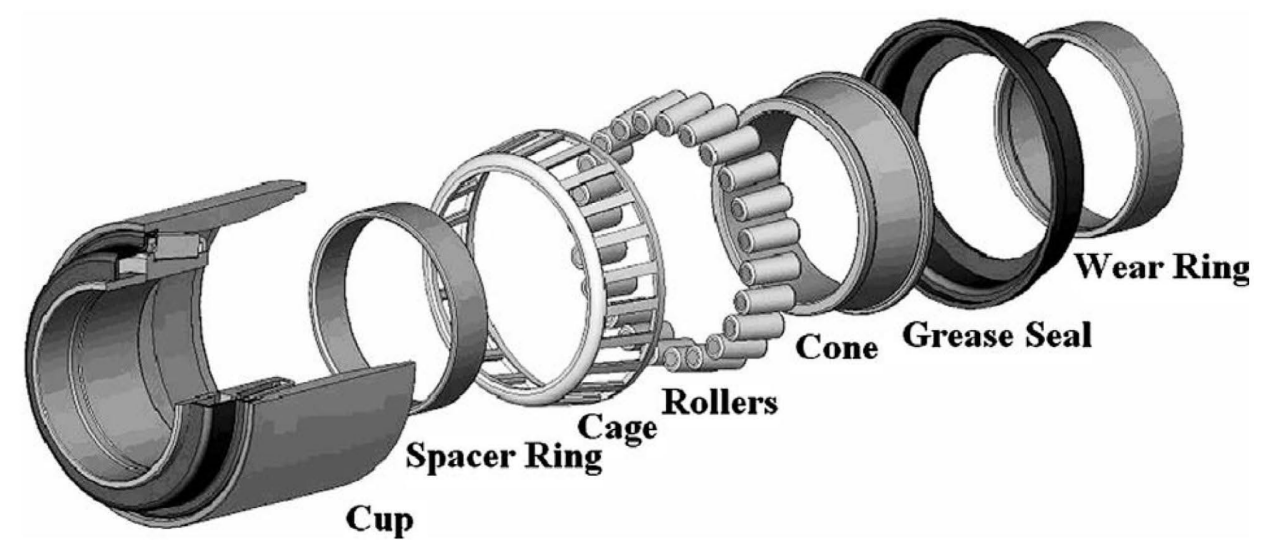

Figure 1. A detailed component view of a typical railroad tapered-roller bearing assembly. 
failed at $129 \mathrm{~km} / \mathrm{h}(80 \mathrm{mph})$. The study concluded that the thermal and mechanical instabilities in a railroad-roller bearing are directly related to the heat generated at the roller-end contacts. The increase in the heat generation is a direct consequence to the grease starvation mechanism caused by the high operating speeds, which results in a larger friction coefficient [12].

From the above discussion, it can be seen that there is a lack of experimental work investigating the temperature distribution within a tapered-roller bearing due to difficulties arising from measuring the temperatures at different locations within a rotating bearing. Therefore, the few studies that were conducted used simplified experimental setups designed to mimic the operation of roller bearings $[13,14]$. The main outcome of some of these experiments was that bearing temperatures predominantly depended on speed and not on load, and that increasing the amount of lubrication slightly raises bearing temperatures.

Other related works have concentrated on theoretical modeling of the thermal effects in plain journal bearings with limited experimental efforts [15-19]. The closest any study came to exploring the heat transfer mechanisms within a bearing is one that looked into the thermal transport conductance between the rings of a roller bearing [20]. The work presented here addresses the immediate need to quantify the heat dissipation paths within railroad tapered-roller bearings in an attempt to comprehend the various mechanisms that could lead to overheating.

\section{Experimental testing}

A total of 21 static thermal tests were conducted with durations of at least $12 \mathrm{~h}$, ensuring that steady state conditions were attained. In the experiments performed, the cage type, the applied load, and the method of cooling were varied to include steel and polyamide cages, loads ranging from 0 to $133,447 \mathrm{~N}(30,000 \mathrm{lb})$, and forced convection cooling at $5 \mathrm{~m} / \mathrm{s}(11.2 \mathrm{mph})$ produced by a fan versus free convection cooling with no fan. Table 1 and Table 2 summarize all the experiments conducted, along with the acquired results. The thermal models used to obtain heat transfer coefficients will be discussed in a later section.

\subsection{Experimental setup}

A Class K $\left(6 \frac{1}{2} \times 12\right)$ tapered-roller bearing (similar to the one shown in Figure 1) mounted on an axle was used to conduct all the static thermal experiments described in this paper. A picture of the setup used to perform the thermal testing is provided in Figure 2. The internal heat source to the bearing was provided using two 400-W resistance heaters. The heaters chosen were approximately $12.7 \mathrm{~mm}$ in diameter and $50.8 \mathrm{~mm}$ in length. Holes were drilled in two rollers to accommodate the resistance heaters. In drilling the holes, special care was taken to minimize air gaps between the heaters and rollers. Excessive air gaps would prevent the heaters from heating the rollers uniformly, and could also cause overheating of the heaters leading to their failure. A picture of the two heated rollers that were used to provide known heat inputs to the bearing assembly is shown in Figure 3.

Thermocouples were strategically mounted on the bearing assembly and axle, as shown in Figures 4 and 5, to collect temperature data throughout the duration of the tests. In experiments $1-7$, a total of 13 thermocouples were used (thermocouples 1-13) to monitor and record the temperature of the bearing assembly. The locations of those thermocouples are shown in Figure 4, excluding thermocouple 16, which was

Table 1. A summary of all the experiments performed using steel cages for extended periods of time along with the obtained overall heat transfer coefficient, $H_{1}$, of the cone/axle side

\begin{tabular}{|c|c|c|c|c|c|c|c|}
\hline Exp. \# & $\begin{array}{l}\text { External } \\
\text { cooling }(\mathrm{m} / \mathrm{s})\end{array}$ & Load (N) & $Q_{\text {in }}(W)$ & $\begin{array}{l}\text { Steady state } \\
\text { roller temp. }\left({ }^{\circ} \mathrm{C}\right)\end{array}$ & $\begin{array}{l}\text { Cage type } \\
\text { /grease }\end{array}$ & $R\left(H_{1} / H_{\mathrm{o}}\right)$ & $H_{1}(\mathrm{~W} / \mathrm{K})$ \\
\hline 1 & 5.0 (sym) & No load & 645.0 & 563.3 & Steel/No & 6.24 & 55.3 \\
\hline 2 & 5.0 (sym) & 88,964 & 645.0 & 516.6 & Steel/No & 6.27 & 55.6 \\
\hline 3 & 5.0 (sym) & Varied load 0-88,964 & 645.0 & 540.4 & Steel/No & 7.39 & 65.5 \\
\hline 4 & 5.0 (sym) & 44,482 & 645.0 & 534.8 & Steel/No & 5.98 & 53.0 \\
\hline 5 & 5.0 (sym) & 133,447 & 645.0 & 506.2 & Steel/No & 6.09 & 54.0 \\
\hline 6 & 5.0 (sym) & Varied load 0-88,964 & 647.0 & 542.5 & Steel/No & 6.57 & 58.2 \\
\hline 7 & No fan & 133,447 & 655.0 & 586.3 & Steel/No & 7.93 & 33.9 \\
\hline 8 & 5.0 (sym) & 44,482 & 686.0 & 539.4 & Steel/No & 5.85 & 51.8 \\
\hline 9 & 5.0 (sym) & 88,964 & 690.4 & 536.7 & Steel/No & 6.25 & 55.4 \\
\hline 10 & 5.0 (sym) & 133,447 & 661.5 & 525.3 & Steel/No & 5.49 & 48.6 \\
\hline 11 & 5.0 (sym) & No load & 656.9 & 578.1 & Steel/No & 7.43 & 65.8 \\
\hline 12 & 5.0 (sym) & Varied load 0-111,206 & 653.8 & 546.8 & Steel/No & 5.79 & 51.3 \\
\hline 13 & No fan & 133,447 & 665.4 & 577.6 & Steel/No & 6.50 & 27.8 \\
\hline 14 & No fan & 133,447 & 668.0 & 581.8 & Steel/No & 7.03 & 30.1 \\
\hline
\end{tabular}

The average overall heat transfer coefficient of the bearing cup, $H_{0}=8.86 \mathrm{~W} / \mathrm{K}$ [forced convection] and $4.28 \mathrm{~W} / \mathrm{K}$ [free convection], acquired utilizing the zero-order model, was used as an input for the first-order model to obtain the results summarized here.

Table 2. A summary of all the experiments performed using polyamide cages for extended periods of time along with the obtained overall heat transfer coefficient, $H_{1}$, of the cone/axle side

\begin{tabular}{|c|c|c|c|c|c|c|c|}
\hline Exp. \# & $\begin{array}{l}\text { External } \\
\text { cooling }(\mathrm{m} / \mathrm{s})\end{array}$ & Load (N) & $Q_{\text {in }}(W)$ & $\begin{array}{l}\text { Steady state } \\
\text { roller temp. }\left({ }^{\circ} \mathrm{C}\right)\end{array}$ & $\begin{array}{l}\text { Cage type } \\
\text { /grease }\end{array}$ & $R\left(H_{1} / H_{\mathrm{o}}\right)$ & $H_{1}(\mathrm{~W} / \mathrm{K})$ \\
\hline 15 & 5.0 (sym) & No load & 198.9 & 228.8 & Polyamide/Yes & 9.15 & 65.1 \\
\hline 16 & 5.0 (sym) & 44,482 & 200.8 & 223.5 & Polyamide/Yes & 8.39 & 59.7 \\
\hline 17 & 5.0 (sym) & 88,964 & 201.1 & 214.9 & Polyamide/Yes & 8.10 & 57.7 \\
\hline 18 & 5.0 (sym) & 133,447 & 199.0 & 210.0 & Polyamide/Yes & 7.55 & 53.8 \\
\hline 19 & 5.0 (sym) & Varied load 0-111,206 & 200.7 & 211.2 & Polyamide/Yes & 7.39 & 52.6 \\
\hline 20 & No fan & 133,447 & 206.2 & 243.0 & Polyamide/Yes & 7.84 & 29.6 \\
\hline 21 & No fan & 133,447 & 202.2 & 243.9 & Polyamide/Yes & 7.49 & 28.2 \\
\hline
\end{tabular}

The average overall heat transfer coefficient of the bearing cup, $H_{0}=7.12 \mathrm{~W} / \mathrm{K}$ [forced convection] and $3.77 \mathrm{~W} / \mathrm{K}$ [free convection], acquired utilizing the zero-order model, was used as an input for the first-order model to obtain the results summarized here. 


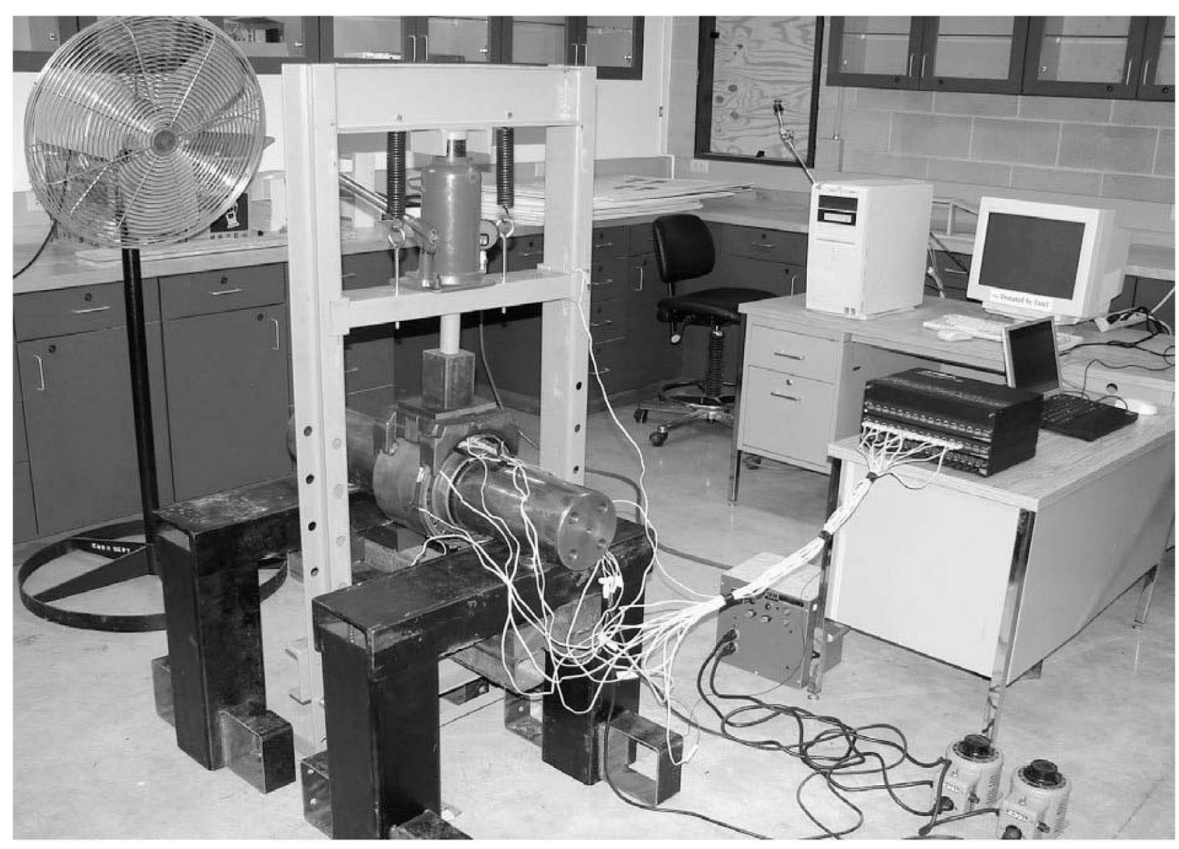

Figure 2. A picture of the experimental setup used to conduct the static thermal testing.

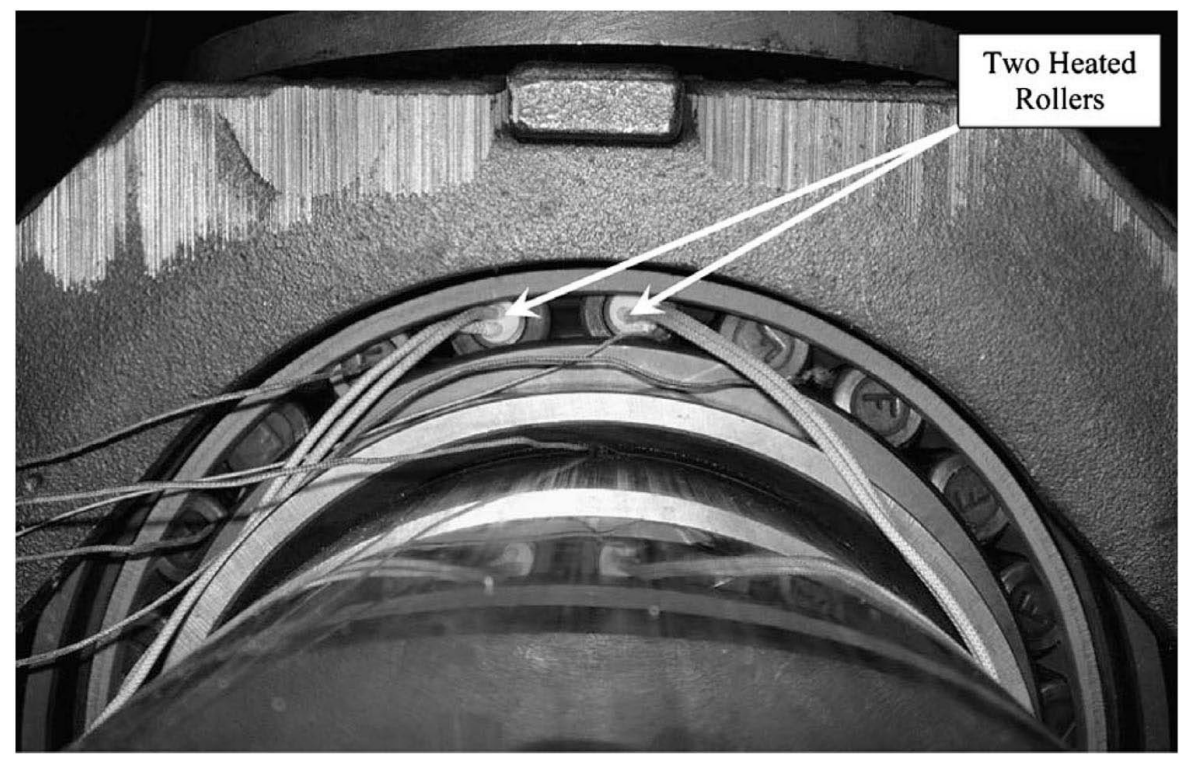

Figure 3. Close-up view of the two heated rollers used to provide known heat inputs to the bearing assembly.

added for the remaining experiments. In addition, thermocouple 13, which is not shown in Figure 4 and Figure 5, was used to monitor and record the ambient room temperature surrounding the experimental setup. This thermocouple can be seen in the picture provided in Figure 2 as the only thermocouple wire attached to the frame of the experimental setup and not the bearing assembly itself. In the remaining experiments (experiments 8-21), three additional thermocouples were added, thermocouples 14-16, with the purpose of monitoring and recording the temperature of the axle $16 \mathrm{~cm}$ away from the bearing assembly (thermocouple 14), the temperature of the adapter plate sitting on top of the bearing assembly and used to apply the load (thermocouple 15), and the temperature of the lower contact area between the inner cone and the axle (thermocouple 16). The locations of thermocouples 14 and 16 can be seen in Figure 4 and Figure 5. In addition, Figure 5 also illustrates where the load was applied on the bearing during the experiments. Not shown is the location of thermocouple 15 which was placed directly on top of the adapter plate to monitor its temperature rise with time. Thermocouples 4-11 were all mounted at the same axial location on the cup, corresponding to the middle of the hot rollers. Thermocouples 1 and 2 were fixed to the two hot rollers 1 and 2, respectively; thermocouple 3 was attached to one of the neighboring rollers, and thermocouples 12 and 16 were placed at the upper and lower contact areas between the inner cone and the axle, as shown in Figure 4. Silver solder was used to attach thermocouples 1, 2 and 3 to the rollers; a large hose clamp was used to fix thermocouples 4-11 to the circumference of the bearing cup; thermocouples 12 and 16 were wedged tightly in the contact areas between the inner cone and the axle; and finally, high temperature Kapton tape was utilized to attach thermocouples 14 and 


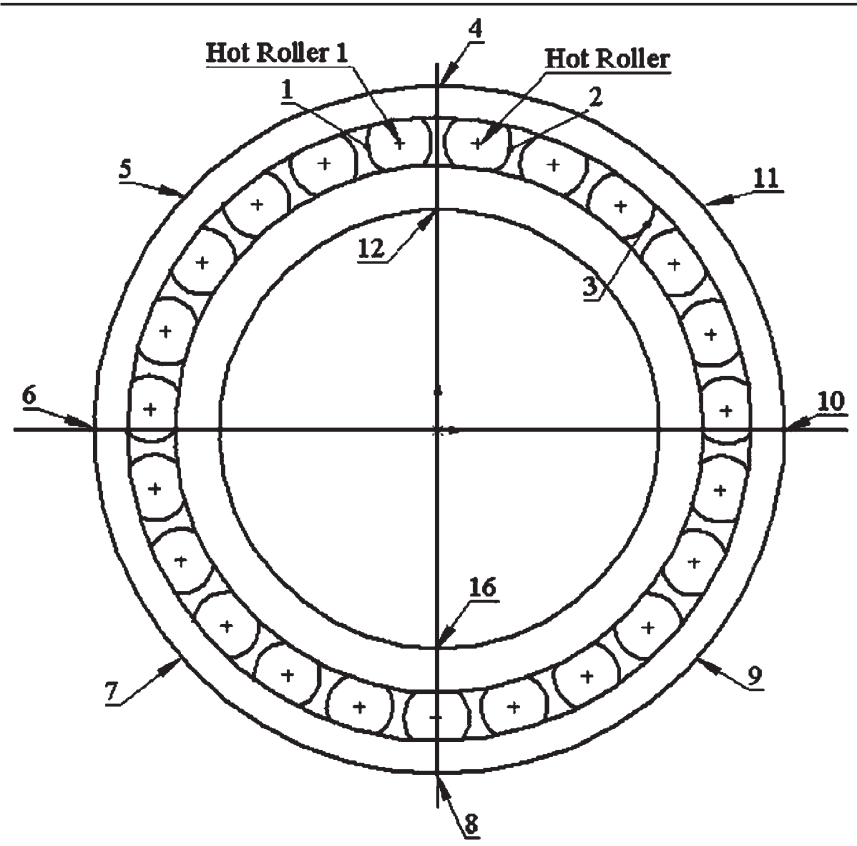

Figure 4. A schematic diagram showing the locations of the thermocouples on the bearing assembly. Thermocouples 1,2 , and 3 are attached to rollers, thermocouples 4-11 are fixed to the bearing cup, and thermocouples 12 and 16 are placed at the upper and lower contact areas between the inner cone and the axle, respectively.

15 to the axle and the bearing adapter, respectively. The thermocouples used to measure temperature in this study were Ktype thermocouples.

Data acquisition was performed utilizing the Omega Engineering OMB-ChartScan-1400 data acquisition system equipped with a 16-channel temperature card. The data acquisition system allows the user to control all aspects of the data acquisition process as well as display the real-time data onscreen and record it in a spreadsheet for later analysis. In addition, the data acquisition system has an added feature which allows for automatic cold-junction temperature compensation for all common thermocouple types. A ground wire was attached to the bearing assembly using high temperature Kapton tape, and then connected to the data acquisition system to eliminate any signal interference. Finally, load was applied to the bearing assembly utilizing a 20-tonf $(40,000-1 b f)$ hydraulic press which can be seen in Figure 2.

Power was delivered to the two resistance heaters using two variable AC power supplies (variacs) visible in the bottom right hand side of Figure 2. An isolation transformer was used to filter out the noise from the AC power supplies and eliminate the interference with the data acquisition system. Separate Instek GW Model GDM 8135 digital multi-meters connected in series were used to continuously monitor the current flowing through each heater. The voltage input to each resistance heater was measured using two $\mathrm{CHY} 20$ multi-meters connected in parallel. The power input to each heater is calculated by multiplying the voltage and current. The voltage and current were measured and recorded every hour. The power input, $Q_{\text {in }}$, reported for each experiment represents the average of all the power input values obtained during each test. A hot wire anemometer was used to measure the velocity of the air stream produced by the fan that was directed towards the bearing assembly to achieve forced convection cooling.

\subsection{Experimental procedure}

For consistency, the same experimental procedure was implemented for all the static experiments conducted for this study. To begin the experiment, the fan was turned on for experiments with forced convection, and the appropriate load was applied using the hydraulic press. The data acquisition software was then initiated and the program input parameters were checked. Before supplying power to the resistance heaters, the data acquisition system was initiated, and $120 \mathrm{~s}$ worth of data were acquired and displayed on-screen to ensure that all thermocouples read room temperature. Both variacs were then adjusted to the desired power output with the aid of the digital multi-meters. The software was set to acquire $12 \mathrm{~h}$ of temperature data for experiments with forced convection and $18 \mathrm{~h}$ of data for experiments with free convection, at a sampling rate of $64 \mathrm{~Hz}$ (i.e., 64 Samples/s), while averaging every $20 \mathrm{~s}$ to produce smoother temperature profiles. The software produced a spreadsheet that consisted of 17 columns of data with the first column containing the time stamp $(20 \mathrm{~s}$ intervals), and the remaining 16 columns containing the temperature data (averaged over $20 \mathrm{~s}$ intervals) from the 16 thermocouples, respectively.

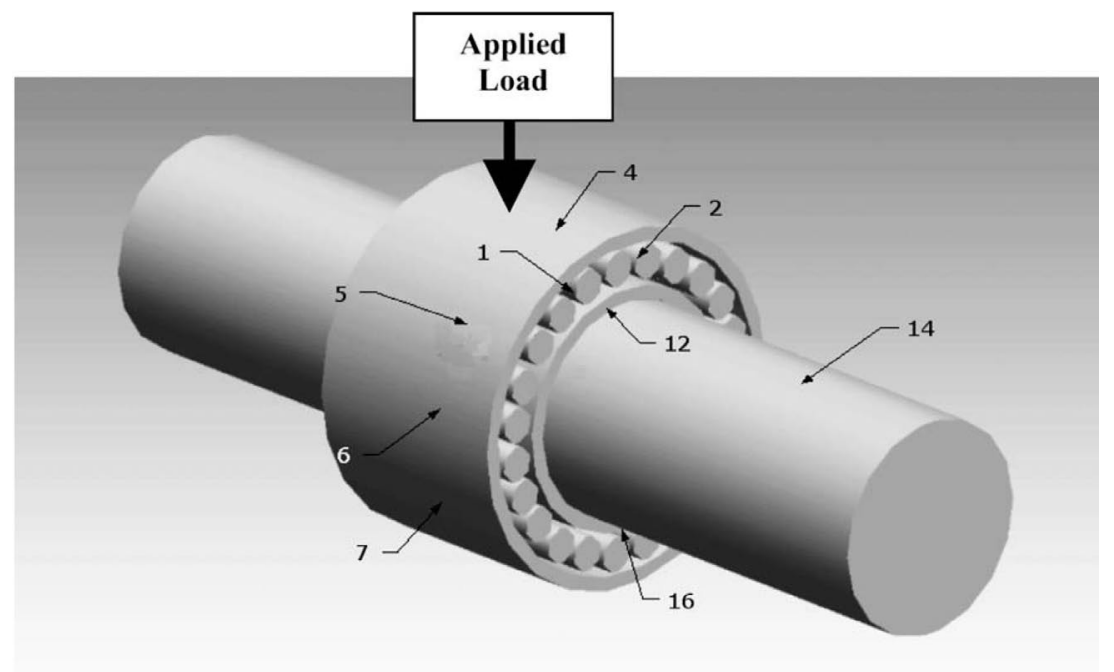

Figure 5. A schematic diagram showing the location of thermocouples 12, 14, and 16 on the axle, and the point of application of the load on the bearing assembly. 


\section{Theoretical models}

Based on the time-history of the temperature data, a thermal model was sought that would reproduce the shape of the data with the fewest possible undetermined parameters. Rather than study the entire bearing, attention was focused on the outer bearing race, called the cup, because this part of an in-service bearing is scanned by the infrared-sensing temperature measurement equipment (the trackside hot-box detector). A successful model will allow us to explore the hypothesis that one or two hot rollers are implicated in some overheating of bearings, by answering this question: what amount of heat, when introduced at one or two rollers, raises the cup temperature to levels sufficient to cause the bearing to be removed from service?

Naturally, the simplest theoretical model was investigated first [21]. This model utilized the zero-order lumped capacitance theory which gives a straightforward transient response. Upon detailed analysis and systematic comparisons between the experimentally acquired data and the zero-order model, it was found that the simple model could not predict the late rise observed in the experimental cup temperature. Therefore, a first-order model was sought that can account for the aforementioned late rise in temperature without drastically increasing the complexity of the theoretical modeling. After several iterations, a first-order thermal model with conduction was developed that produced temperature trends which followed very closely the temperatures acquired experimentally. The results summarized in Tables 1 and 2 were obtained utilizing the two abovementioned theoretical thermal models. A detailed description of these models is presented in the following two sections.

\subsection{Zero-order model}

The zero-order (lumped capacitance) model includes two terms; heat introduced into the bearing and heat storage in the cup. The model contains a single undetermined parameter which represents the overall heat transfer coefficient of the bearing cup, $H_{\mathrm{o}}$. The zero-order model is described by the following equations:

$$
\begin{aligned}
& Q_{\text {in }}-H_{0}\left(T_{1}-T_{\mathrm{a}}\right)=M_{\mathrm{c}} c \frac{\mathrm{d} T_{1}}{\mathrm{~d} t}, \\
& T_{1}(t=0)-T_{\mathrm{a}}=0 .
\end{aligned}
$$

The zero-order model given in Equation (1) is a linear, first-order, non-homogeneous differential equation. It may be transformed into a homogeneous equation by the use of a new variable $\theta=T_{1}-T_{\mathrm{a}}-Q_{\text {in }} / H_{\mathrm{o}}$. With this new variable, Equations (1) and (2) may be re-written as [22]

$$
\begin{aligned}
& \frac{\mathrm{d} \theta}{\mathrm{d} t}+\frac{H_{\mathrm{o}}}{M_{\mathrm{c}} c} \theta=0, \\
& \theta(0)=-\frac{Q_{\mathrm{in}}}{H_{\mathrm{o}}} .
\end{aligned}
$$

The solution to the above initial-value problem is given by

$$
\begin{aligned}
& \theta(t)=-\frac{Q_{\text {in }}}{H_{\mathrm{o}}} \mathrm{e}^{-H_{0} t /\left(M_{\mathrm{c}} c\right)}, \quad \text { or, } \\
& T_{1}(t)-T_{\mathrm{a}}=\frac{Q_{\text {in }}}{H_{\mathrm{o}}}\left[1-\mathrm{e}^{-H_{\mathrm{o}} t /\left(M_{\mathrm{c}} c\right)}\right] .
\end{aligned}
$$

This expression gives a value for the bearing cup temperature as a function of time, heat input rate, mass and composition of the cup, and an overall heat transfer coefficient. Through systematic comparisons with the experimental data, the zero-order model may be used to estimate a value for the cup overall heat transfer coefficient, $H_{0}$. This parameter can then be used to get quick estimates of the theoretical bearing cup temperature for a given heat input utilizing Equation (6).

A comment is in order on the cup temperature. A rotating bearing with one or two hot rollers would have the hot rollers sweeping round and round the cup, uniformly heating the cup, even at modest train speeds. Our experimental bearing is nonrotating, so the cup temperature is high near the hot rollers and lower around the circumference of the cup. To simulate the averaging of cup temperature that a rotating bearing would provide, we used the spatial-average of the measured cup temperatures to obtain a single temperature history for comparison with the model. The spatial-averaging simulates the "time averaging" that a rotating bearing would provide. A numerical example will provide a framework for understanding this averaging effect. In a train moving at a leisurely $11.2 \mathrm{~m} / \mathrm{s}(25 \mathrm{mph})$, a $91.4 \mathrm{~cm}$ (36 in.) diameter wheel sees 234 revolutions per minute (rpm). Later we present data to show that the thermal response time of the bearing cup is measured in tens of minutes, indicating that thousands of roller orbits would spread the heating over the entire bearing cup on a moving train. Further discussion of this issue is provided elsewhere [23].

\subsection{First-order model}

The zero-order model, although having the virtue of simplicity, is of limited accuracy because one heat transfer coefficient, $H_{\mathrm{o}^{\prime}}$ can only approximately represent the several heat-loss mechanisms present in the bearing. For example, the bearing is in contact with air over its outer diameter and it is in contact with the axle over its inner diameter. A heat transfer coefficient is a good way to characterize heat loss to the fixed-temperature air; however, a heat transfer coefficient alone is not a good way to characterize heat loss to the axle, because the axle temperature slowly changes during the experiment. In this

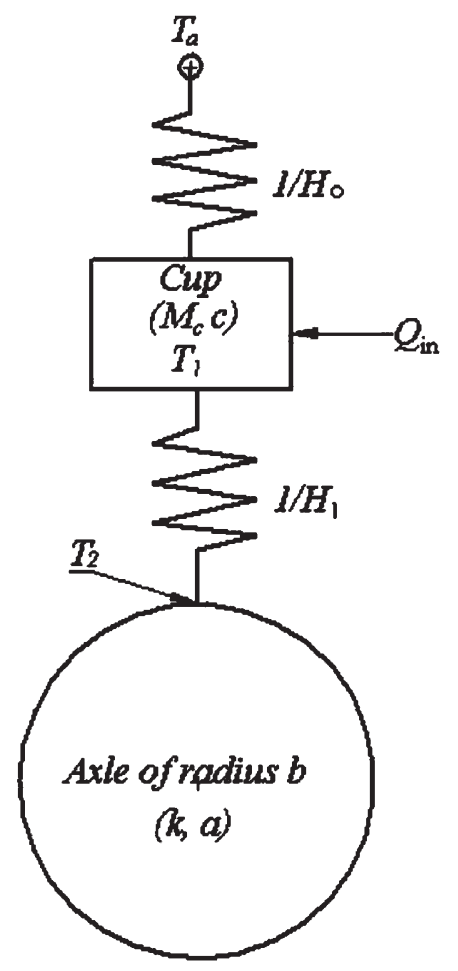

Figure 6. Schematic diagram of the thermal resistance circuit used to construct the first-order model. 
section a first-order model is developed to include an additional parameter to describe axle-side heat loss from the bearing.

A schematic diagram of the first-order model is shown in Figure 6. The first-order model is built on the assumption that the bearing cup receives a heat input which is then dissipated in two ways; heat transfer to the air represented by the thermal resistance $1 / H_{\mathrm{o}^{\prime}}$ and conduction to the axle represented by the thermal resistance $1 / H_{1}$. An energy balance performed for the bearing cup yields the following governing equation:

$$
Q_{\text {in }}-H_{0}\left(T_{1}-T_{\mathrm{a}}\right)-H_{1}\left(T_{1}-T_{2}\right)=\left(M_{\mathrm{c}} c\right) \frac{\mathrm{d} T_{1}}{\mathrm{~d} t} .
$$

The temperatures $T_{\mathrm{a}^{\prime}} T_{1}$, and $T_{2}$ represent, respectively, the ambient temperature surrounding the bearing assembly, the bearing cup temperature, and the temperature at the surface of the axle in the region of contact between the axle and the inner cone. The temperature in the cup, $T_{1}$, can be found from Equation (7) if the axle temperature, $T_{2}$, can be stated as a function of unknown temperature $T_{1}$. This relationship between $T_{1}$ and $T_{2}$ will be found from the well-known solution for the radial heat conduction into a cylinder caused by a step-change in external temperature.

If the axle temperature is initially at $T_{a^{\prime}}$ the temperature in the axle caused by a step-change in temperature $T_{1}$ is given by [24, p. 202]

$$
\theta^{*}=\frac{T(r, t)-T_{1}}{T_{\mathrm{a}}-T_{1}}=C_{1} J_{o}\left(\zeta_{1} r^{*}\right) \mathrm{e}^{\left(-\zeta_{1}^{2} F o\right)},
$$

where $\theta^{*}$ is the dimensionless temperature, $r^{*}=1$ at the surface of the cylinder, Fo is the dimensionless Fourier number, $F o=a t / b^{2}, a$ is the thermal diffusivity, $b$ is the radius of the cylinder, and $t$ is the time. In Equation (8), $J_{o}$ is the Bessel function of the first kind. The values of the eigenvalue $\zeta_{1}$ are roots of the following transcendental equation

$$
\zeta_{1} J_{1}\left(\zeta_{1}\right)-\left(h_{1} b / k\right) J_{0}\left(\zeta_{1}\right)=0
$$

and coefficient $C_{1}$ is given by

$$
C_{1}=\frac{2}{\zeta_{1}} \frac{J_{1}\left(\zeta_{1}\right)}{J_{0}^{2}\left(\zeta_{1}\right)+J_{1}^{2}\left(\zeta_{1}\right)}
$$

Numerical values for $\zeta_{1}$ are tabulated versus the Biot number (Bi) [24, p. 493]. The above expression for the dimensionless temperature, most accurate for Fourier numbers greater than 0.2 , is the first term of a well-known infinite series solution.

Next the response of the cylinder (axle) to an arbitrary change in temperature $T_{1}$ will be found by use of a superposition integral. Evaluate $\theta^{*}$ at the surface of the cylinder $(r=b)$ and add and subtract $T_{\mathrm{a}}$ :

$$
\left.\theta^{*}\right|_{r=b}=\frac{T_{2}-T_{1}}{T_{\mathrm{a}}-T_{1}}=\frac{\left(T_{2}-T_{\mathrm{a}}\right)-\left(T_{1}-T_{\mathrm{a}}\right)}{T_{\mathrm{a}}-T_{1}} .
$$

Solve the above relation for $\left(T_{2}-T_{a}\right)$ :

$$
T_{2}-T_{\mathrm{a}}=\left(T_{1}-T_{\mathrm{a}}\right)\left(1-\theta^{*}\right) .
$$

This is the response of the cylinder surface to a step change of size $\left(T_{1}-T_{a}\right)$, which means that the unit-step response is $\left(1-\theta^{*}\right)$. The unit-step response can be differentiated to find the impulse response, which is also known as the Green's function (see for example [25])

$$
G(t)=\frac{\mathrm{d}}{\mathrm{d} t}\left(1-\theta^{*}\right)=C_{1}\left(\frac{\zeta_{1}^{2} \alpha}{b^{2}}\right) J_{0}\left(\zeta_{1}\right) \mathrm{e}^{-\zeta_{1}^{2} F o} .
$$

Then, temperature $T_{2}$ caused by an arbitrarily varying $T_{1}$ can be written in terms of the following superposition integral

$$
T_{2}(t)-T_{\mathrm{a}}=\int_{\tau=0}^{t}\left[T_{1}(\tau)-T_{\mathrm{a}}\right] G(t-\tau) \mathrm{d} \tau
$$

The above equations can be normalized and simplified utilizing the following definitions:

$$
\begin{aligned}
T_{n}^{+} & =\frac{T_{n}-T_{\mathrm{a}}}{Q_{\text {in }} / H_{\mathrm{o}}} ; \quad R=\frac{H_{1}}{H_{\mathrm{o}}} ; \quad \tau=\frac{M_{\mathrm{c}} \mathrm{C}}{H_{\mathrm{o}}} ; \quad \sigma=\frac{\zeta_{1}^{2} \alpha \tau}{b^{2}} ; \\
t^{+} & =\frac{t}{\tau} ; \quad J=C_{1} J_{o}\left(\zeta_{1}\right) .
\end{aligned}
$$

Applying the definitions provided in Equation (15) to Equations (12) and (13), Equation (14) can be re-written as follows:

$$
T_{2}^{+}\left(t^{+}\right)=\int_{u=0}^{t^{+}} T_{1}^{+}(u)\left[\sigma \sigma \mathrm{e}^{-\sigma\left(t^{+}-u\right)}\right] \mathrm{d} u .
$$

Next, the energy balance for $T_{1}$, Equation (7), and the above relation for $T_{2}$ will be solved together with the Laplace transform method. Taking the Laplace transform of Equation (16) and noting that $L\left(T^{+}\right)=\bar{T}$, Equation (16) becomes

$$
\bar{T}_{2}=\bar{T}_{1} J \frac{\sigma}{\sigma+s} .
$$

Equation (17) represents the response of the axle in Laplace space. Using the definitions provided by Equation (15), Equation (7) can be non-dimensionalized by dividing the entire equation by $Q_{\text {in }}$ and performing some mathematical manipulations. The resulting equation, Equation (18), given by

$$
1-T_{1}^{+}-R\left(T_{1}^{+}-T_{2}^{+}\right)=\frac{\mathrm{d} T_{1}^{+}}{\mathrm{d} t^{+}}
$$

is the normalized energy balance equation that governs heat transfer from the bearing cup to the surroundings and to the axle. Taking the Laplace transform of Equation (18) yields

$$
\frac{1}{s}-\bar{T}_{1}-R\left(\bar{T}_{1}-\bar{T}_{2}\right)=s \bar{T}_{1}-T_{i} \quad\left(T_{i}=0\right) .
$$

Substituting for $\bar{T}_{2}$ from Equation (17) and rearranging with some mathematical manipulation, Equation (19) can be rewritten as

$$
\bar{T}_{1}=\frac{\sigma+s}{s\left[\sigma(1+R-R J)+s(1+R+\sigma)+s^{2}\right]},
$$

which represents the theoretical bearing cup temperature in Laplace space. The transient thermal response of the bearing cup can be obtained by taking the Laplace inverse of Equation (20). The Laplace inverse transform was carried out with symbolic manipulation software. The final result, given by Equation (21), is the theoretical normalized transient temperature of the bearing cup, $T_{1}^{+}(t)$, in terms of $\sigma, R, J$ and $t^{+}$as defined by Equation (15)

$$
\begin{aligned}
T_{1}^{+}= & {\left[\frac{\cos \left(0.5\left(2 \sigma+2 R \sigma-4 \sigma R J-1-2 R-R^{2}-\sigma^{2}\right)^{0.5} t^{+}\right)}{(-1-R+R J)}\right] } \\
& \cdot \mathrm{e}^{-0.5(1+\sigma+R) t^{+}} \\
& +\left[\frac{(-\sigma+R+1-2 R J)\left(2 \sigma+2 R \sigma-4 \sigma R J-1-2 R-R^{2}-\sigma^{2}\right)^{0.5}}{(-1-R+R J)\left(-2 \sigma-2 R \sigma+4 \sigma R J+1+2 R+R^{2}+\sigma^{2}\right)}\right] \\
& \cdot \sin \left(0.5\left(2 \sigma+2 R \sigma-4 \sigma R J-1-2 R-R^{2}-\sigma^{2}\right)^{0.5} t^{+}\right) \\
& \cdot \mathrm{e}^{-0.5(1+\sigma+R) t^{+}}-\frac{1}{(-1-R+R J)}
\end{aligned}
$$

This is the (normalized) bearing cup temperature as a function of bearing geometry, as a function of time, and as a function of coefficients $H_{\mathrm{o}}$ and $H_{1}$. The dimensional form of the bearing cup temperature can then be obtained using the definition provided in Equation (15) as follows: 


$$
T_{1}(t)=\frac{Q_{\text {in }}}{H_{\mathrm{o}}} T_{1}^{+}(t)+T_{\mathrm{a}}
$$

This expression is used in the next section to compare the experimental temperature to the (normalized) model temperature.

\section{Comparison between theoretical models and experimental data}

As mentioned earlier, the results summarized in Tables 1 and 2 were obtained utilizing both the zero- and first-order models. The zero-order model was first used to acquire an average overall heat transfer coefficient for the bearing cup, $H_{\mathrm{o}^{\prime}}$ representing the heat loss from the bearing cup to the surroundings [21]. The $H_{\mathrm{o}}$ parameter was then used as an input for the firstorder model to obtain an overall heat transfer coefficient from the bearing cup to the axle, $H_{1}$. Estimation of the parameters $H_{\mathrm{o}}$ and $H_{1}$ was accomplished utilizing non-linear regression routines available in the MATLAB optimization toolbox. Optimization programs were devised to compare the temperatures given by the zero-order model of Equation (6) and the first-order model of Equation (21) to the spatially-averaged experimental cup temperatures by choosing optimal $H_{\mathrm{o}}$ and $H_{1}$ values that minimize the sum of the least square error. Cup and axle values used are the following: cup mass $M_{c}=11.53 \mathrm{~kg}$; specific heat $c=475 \mathrm{~J} / \mathrm{kg} \mathrm{K}$; thermal diffusivity $a=14.2 \mathrm{E}-6 \mathrm{~m}^{2} / \mathrm{s}$; and axle radius $b=0.0778 \mathrm{~m}$ (properties of 1060 steel at $333 \mathrm{~K}$ ).

It should be noted that the $H_{\mathrm{o}}$ values reported in the headers of Tables 1 and 2 represent the average values obtained for experiments conducted with steel and polyamide cages, respectively. For convenience, Table 3 provides a concise summary of the average overall heat transfer coefficients acquired from all the experiments conducted along with the Biot numbers $(B i)$ needed as inputs for the first-order model.

For comparison, each of the two theoretical models was plotted against the experimental average cup temperature and the graphs are shown in Figures 7-10. Figures 7 and 8 compare the zero-order model to the experimental cup temperature obtained from experiments 5 and 13, respectively, and Figures 9 and 10 are their counterparts for the first-order model. Experiments 5 and 13 were chosen because they represent tests with forced and free convection cooling, respectively. By looking at Figure 7 and Figure 9, it can be seen that the agreement between experiment and model is very good for both models considering the simplicity of the zero-order model. Albeit, the first-order model seems to capture the behavior of the experimental temperature data very well at all times, whereas, the zero-order model matches the experiment at later times but misses the initial temperature transient completely.

The shortcomings of the zero-order model emerge in Figure 8 where the model prediction is plotted against the experimental cup temperature for the free convection cooling test (experiment 13). It is apparent that the zero-order model reaches an asymptotic value and fails to capture the behavior

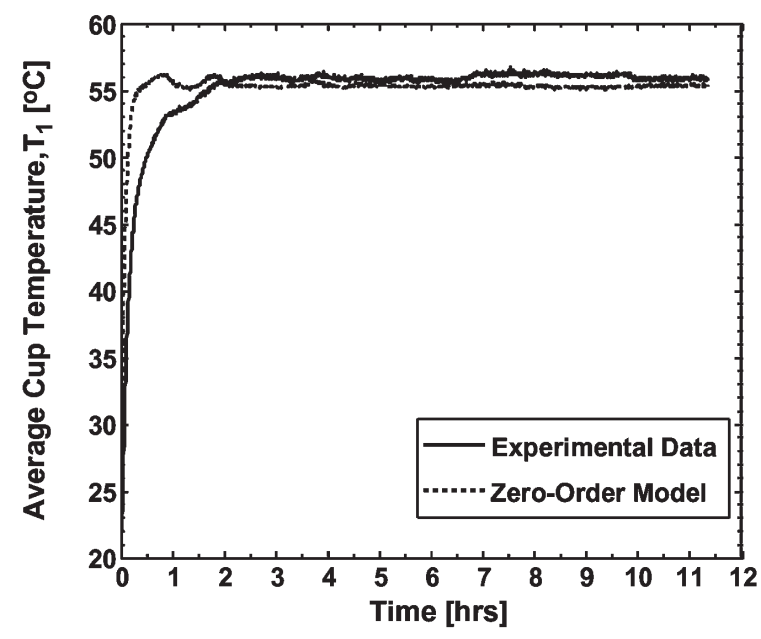

Figure 7. A graph presenting the experimental average cup temperature history along with the zero-order model prediction. [Data taken from experiment 5: air blowing at $5 \mathrm{~m} / \mathrm{s}(11.2 \mathrm{mph}), 133,447 \mathrm{~N}$ $(30,000 \mathrm{lb})$ load, steel cages, total heat input of $645 \mathrm{~W}$.

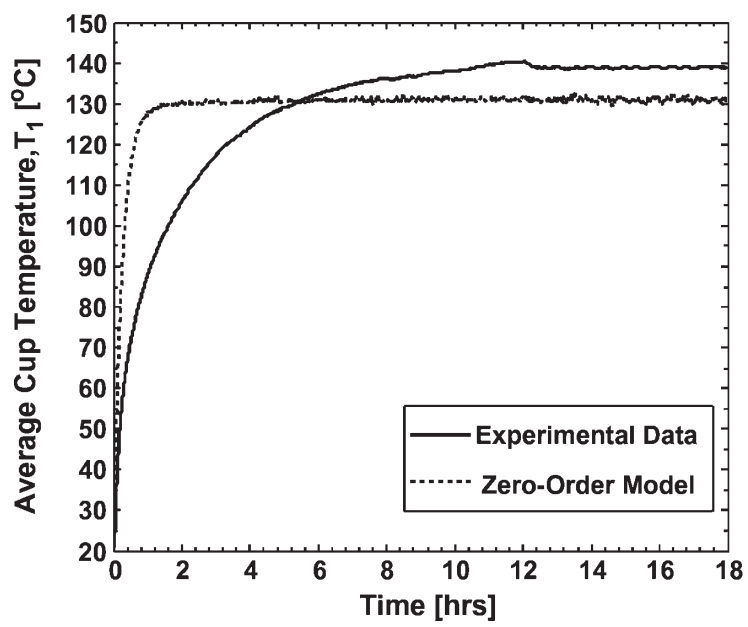

Figure 8. A graph presenting the experimental average cup temperature history along with the zero-order model prediction. [Data taken from experiment 13: quiescent air, 133,447 N (30,000 lb) load, steel cages, total heat input of $665.4 \mathrm{~W}$.]

of the experimental temperature history. Only crude estimates are possible with the zero-order model for free convection cooling cases. On the contrary, the first-order model gives accurate predictions of the cup temperature history regardless of the cooling method, as can be seen in the excellent agreement between model and experiment depicted in Figure 10.

It should be noted that the plots of the remaining tests, not shown here, exhibit very similar behavior to what has been

Table 3. A summary of the results obtained from the static thermal study performed on a Class $\mathrm{K}$ tapered-roller bearing showing the average overall heat transfer coefficients of the bearing cup, $H_{\mathrm{o}^{\prime}}$ and of the cone/axle side, $H_{1}$

\begin{tabular}{|c|c|c|c|c|c|c|}
\hline \multirow[t]{2}{*}{ Class K $\left(6 \frac{1}{2} \times 12\right)$ tapered-roller bearing } & \multicolumn{3}{|c|}{ Forced convection } & \multicolumn{3}{|c|}{ Free convection } \\
\hline & $H_{\mathrm{o}}[\mathrm{W} / \mathrm{K}]$ & $H_{1}[\mathrm{~W} / \mathrm{K}]$ & $B i$ & $H_{\mathrm{o}}[\mathrm{W} / \mathrm{K}]$ & $H_{1}[\mathrm{~W} / \mathrm{K}]$ & $B i$ \\
\hline Bearing was fully assembled using steel cages with no grease & 8.86 & 55.9 & 0.73 & 4.28 & 30.6 & 0.24 \\
\hline Bearing was fully assembled using polyamide cages with grease & 7.12 & 57.8 & 0.51 & 3.77 & 28.9 & 0.16 \\
\hline Appropriate average values for both types of cages & 8.32 & 55.9 & 0.66 & 4.08 & 29.2 & 0.21 \\
\hline
\end{tabular}

Also shown, are the obtained Biot numbers $(\mathrm{Bi})$ needed as inputs for the first-order model. 


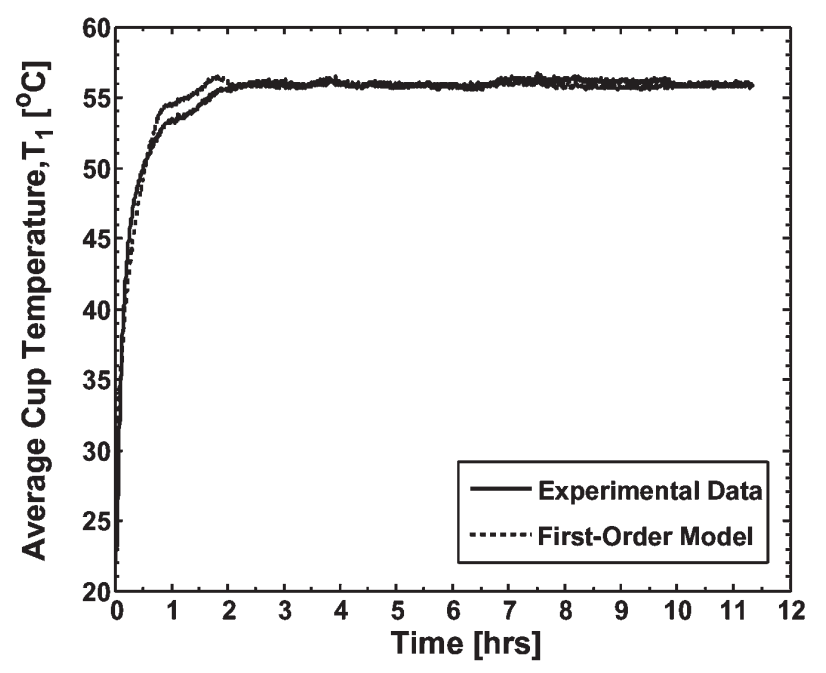

Figure 9. A graph presenting the experimental average cup temperature history along with the first-order model prediction. [Data taken from experiment 5: air blowing at $5 \mathrm{~m} / \mathrm{s}$ (11.2 mph), 133,447 N $(30,000 \mathrm{lb})$ load, steel cages, total heat input of $645 \mathrm{~W}]$.

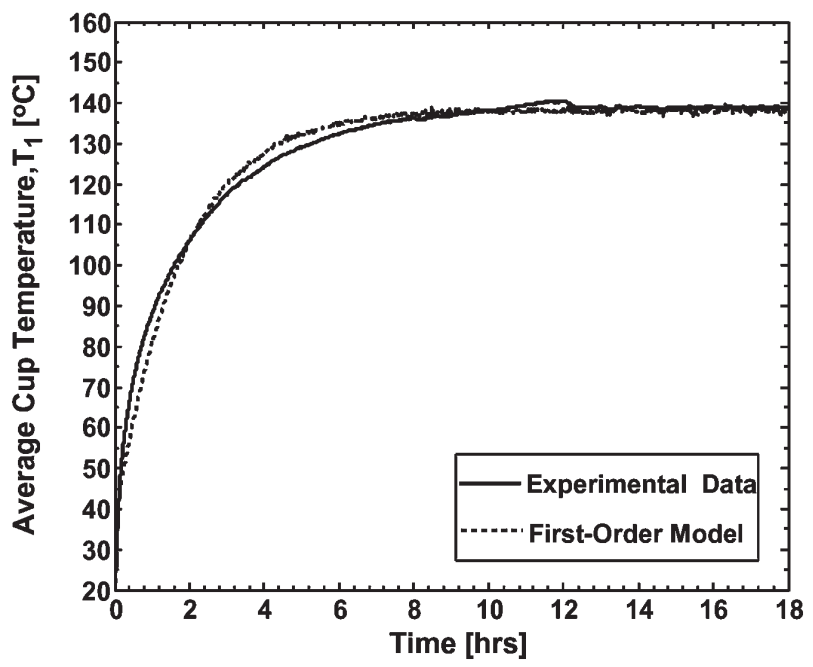

Figure 10. A graph presenting the experimental average cup temperature history along with the first-order model prediction. [Data taken from experiment 13: quiescent air, 133,447 N (30,000 lb) load, steel cages, total heat input of $665.4 \mathrm{~W}$.]

illustrated in Figures 7-10. A discussion of the trends observed under the different loading conditions, cage types, cooling methods, and heat inputs follows.

\section{Discussion of results}

As mentioned earlier, a total of 21 static thermal experiments were performed varying the loading conditions, the method of cooling, the cage type used, and the heat inputs. The results are summarized in Tables 1-3 and illustrated in Figures 7-11. Several conclusions and trends can be drawn from the analysis of those results and are discussed in this section.

The most significant parameter seems to be the method of cooling, as can be seen from the overall heat transfer coefficient values listed in the tables. Experiments with forced convection cooling exhibit overall heat transfer coefficients

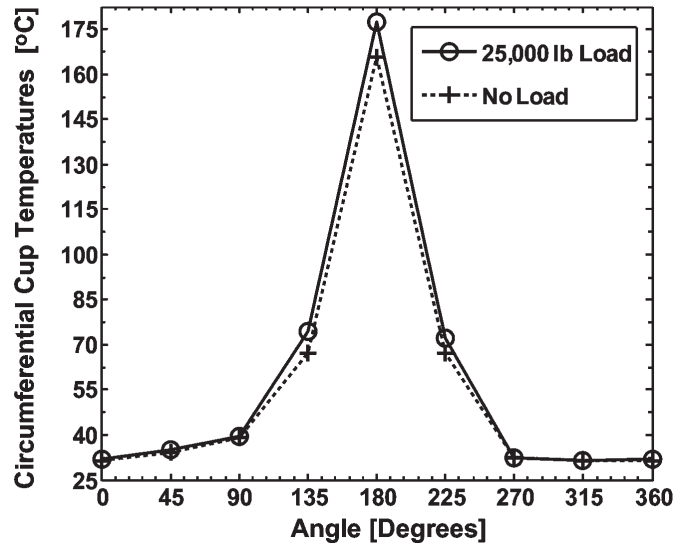

Figure 11. A plot of the circumferential cup temperatures comparing the temperature distribution under loading and unloading conditions. [Data taken from experiment 12: air blowing at $5 \mathrm{~m} / \mathrm{s}(11.2 \mathrm{mi}$ / h), $0-111,206 \mathrm{~N}(0-25,000 \mathrm{lb})$ varied load, steel cages, total heat input of $653.8 \mathrm{~W}$.]

approximately twice as much as those for tests with free convection cooling. In general, loading on the bearing tends to slightly decrease the cone/axle side overall heat transfer coefficient, $H_{1}$, which is understandable since more load translates into a larger contact area between the rollers and the cup, and hence, smaller thermal resistance and easier heat flow. This trend is also strongly supported by the temperature data given in Tables 1 and 2 which demonstrate how the steady state temperature of the heated rollers tends to decrease with increasing load; a clear indication that heat is diffusing easier from the heated rollers to the bearing cup. Yet another proof of how load enhances heat transfer from the rollers to the bearing cup is provided in Figure 11 which presents a plot of the circumferential cup temperatures comparing the temperature distribution under loading and unloading conditions. The circumferential temperature profile shown in Figure 11 is typical of all the static thermal experiments performed for this study. The temperature is a maximum at the region right above the two heated rollers, and decreases systematically as we move around the circumference of the cup until the minimum temperature is reached at the other end, $180^{\circ}$ from the top. The slight asymmetry is caused by the two heated rollers not providing exactly the same heat input. Remember that the two heaters were embedded into two rollers by drilling two holes in the rollers. Although great care was taken to achieve full contact between the heaters and the rollers, small gaps between them can easily account for the aforementioned asymmetry, especially when combined with any minor misalignment in loading. Another observation worth mentioning is the fact that the difference in the temperature distribution between the loaded and unloaded scenarios is only apparent in the upper hemisphere of the bearing cup where the load is applied. In the lower hemisphere, the difference in temperatures is barely discernible, which is a direct consequence of the absence of any applied load in that region.

The effect of cage type and grease on the overall heat transfer coefficients can be seen by comparing the values listed in Table 3. It is apparent that the ratio of the cone/axle side overall heat transfer coefficient to the cup side overall heat transfer coefficient, $H_{1} / H_{\mathrm{o}^{\prime}}$ is slightly higher for the bearing assembled with polyamide cages and grease than for the bearing assembled with steel cages for both forced and free convection cooling. Consequently, this implies that, in the case of polyamide 
cages and grease, a little more heat leaves the bearing through the axle side and a little less heat leaves through the bearing cup when compared to the bearing with steel cages. The aforementioned can be explained by the much lower thermal conductivity of the polyamide cages compared to that of the steel cages which limits the amount of heat that can be transferred to the bearing cup. It should be noted that the presence of grease had very little to no effect on the overall heat transfer coefficient values. The use of grease in the bearing with polyamide cages was essential to protect the cages from damage at elevated roller temperatures. The latter was also the reasoning for limiting the power input to the heaters to about $200 \mathrm{~W}$ in the experiments performed with the polyamide cages. However, an initial experiment performed with the bearing assembled with polyamide cages, and utilizing a $638 \mathrm{~W}$ total power input to the two heaters yielded a similar overall heat transfer coefficient to the ones provided in Table 2. The aforementioned experiment, along with some other tests, is described in detail elsewhere [21].

Finally, a very interesting observation is that, in all the cases investigated, the acquired $H_{1}$ values only varied from 48.6 to $65.8 \mathrm{~W} / \mathrm{K}$ for experiments with forced convection, and from 27.8 to $33.9 \mathrm{~W} / \mathrm{K}$ for tests with free convection. This last remark justifies using the average overall heat transfer coefficients, provided in Table 3, to obtain accurate estimates $(<7 \%$ error) of the bearing cup temperature history for a given heat input, or the amount of heat generated within the bearing for a known cup temperature history.

\section{Conclusions and future work}

The results obtained from the static thermal testing of taperedroller bearings, which are summarized in Tables 1-3, are essential in understanding the heat dissipation paths within these bearings, and offer insight into what heat inputs are required to raise the bearing cup temperature to a specific value. More importantly, the heat transfer models developed for this study, along with the acquired overall heat transfer coefficients, can be used to validate finite element models that we plan to construct to simulate the bearing in operation. For example, being able to predict the roller temperatures for a known outside cup temperature will be of great value to the railroad industry and will be possible using validated finite element models. In addition, these models can be used to investigate numerous scenarios in which heat generated within the bearing is unevenly distributed or is localized in certain regions of the bearing simulating certain defects within the bearing or abnormal operating conditions of bearings in service.

The value of the theoretical modeling performed in this study, and any future finite element modeling to follow, lies in the undisputed fact that simulations are the most economical means of obtaining prompt answers regarding the thermal behavior of tapered-roller bearings in service. Once these models have been utilized to thoroughly investigate a scenario of interest, carefully planned experiments can be conducted to verify the theoretical predictions. The aforementioned will greatly reduce the number of tests performed which will save the investigator time and effort while cutting down on costs.

\section{Acknowledgments}

The authors wish to thank BRENCO Inc., one of the Amsted Rail companies, for support of this work and permission to publish.

\section{References}

[1] S. Karunakaran and T. W. Snyder, Bearing temperature performance in freight cars, in: Proceedings of the ASME RTD 2007 Fall Technical Conference, Chicago, IL, September 11-12, 2007.

[2] C. M. Tarawneh, B. M. Wilson, K. D. Cole, and M. Reed, A metallurgical and experimental investigation into sources of warm bearing trending, in: Proceedings of the 2008 IEEE/ASME Joint Rail Conference (63028), Wilmington, DE, April 22-23, 2008.

[3] J. Conyers, Learning from bearing failure, Plant Eng. (2003), pp. 44-46.

[4] Y. Li, T. R. Kurfess, and S. Y. Liang, Stochastic prognostics for rolling element bearings, Mech. Syst. Signal Process. 14 (5) (2004), pp. $747-762$.

[5] J. L. A. Ferreira, J. C. Balthazar, and A. P. N. Araujo, An investigation of rail bearing reliability under real conditions of use, Eng. Fail. Anal. 10 (2003), pp. 745-758.

[6] T. Williams, X. Ribadeneira, S. Billington, and T. Kurfess, Rolling element bearing diagnostics in run-to-failure lifetime testing, Mech. Syst. Signal Process. 15 (5) (2001), pp. 979-993.

[7] G. B. Anderson, Acoustic detection of distressed freight car roller bearings, in: Proceedings of the 2007 JRCICE Spring Technical Conference, Pueblo, CO, March 13-16, 2007.

[8] B. Liu, S. F. Ling, and R. Gribonval, Bearing failure detection using matching pursuit, NDTEE Int. 35 (2002), pp. 255-262.

[9] D. L. Dunnuck, Steady-state temperature and stack-up force distributions in a railroad roller bearing assembly, MS thesis, University of Illinois at Urbana-Champaign, Urbana, IL, 1992.

[10] H. Wang, Axle burn-off and stack-up force analyses of a railroad roller bearing using the finite element method, Ph.D. thesis, University of Illinois at Urbana-Champaign, Urbana, IL, 1996.

[11] S. Wang, C. Cusano, and T. F. Conry, A dynamic model of the torque and heat generation rate in tapered roller bearings under excessive sliding conditions, Tribol. Trans. 36 (4) (1993), pp. 513-524.

[12] D. B. Kletzli, C. Cusano, and T. F. Conry, Thermally induced failures in railroad tapered roller bearings, Tribol. Trans. 42 (4) (1999), pp. 824-832.

[13] N. E. Farnfield, Thermal investigations of roller bearings, Tribology 5 (3) (1972), p. 104.

[14] M. R. Hoeprich, Rolling-element bearing internal temperatures, Tribol. Trans. 39 (4) (1996), pp. 855-858.

[15] X. L. Wang and K. Q. Zhu, Numerical analysis of journal bearings lubricated with micropolar fluids including thermal and cavitating effects, Tribol. Int. 39 (3) (2006), pp. 227-237.

[16] M. Fillon and J. Bouyer, Thermohydrodynamic analysis of a worn plain journal bearing, Tribol. Int. 37 (2004), pp. 129-136.

[17] X. L. Wang, K. Q. Zhu, and S. Z. Wen, Thermohydrodynamic analysis of journal bearings lubricated with couple stress fluids, Tribol. Int. 34 (2001), pp. 335-343.

[18] X. K. Li, A. R. Davies, and T. N. Phillips, A transient thermal analysis for dynamically loaded bearings, Comput. E Fluids 29 (2000), pp. 749-790.

[19] M. T. Ma and C. M. Taylor, An experimental investigation of thermal effects in circular and elliptical plain journal bearings, Tribol. Int. 29 (1) (1996), pp. 19-26.

[20] J. M. Briot, B. Bourouga, and J. P. Bardon, Thermal transport conductance between the rings of a roller bearing, Revue Generale De Thermique 36 (8) (1997), pp. 610-623.

[21] C. M. Tarawneh, K. D. Cole, B. M. Wilson, and K. J. Freisen, A lumped capacitance model for the transient heating of railroad tapered roller bearings, in: Proceedings of the 2007 ASEE-GSW Annual conference (T2C5), South Padre Island, TX, March 28-30, 2007.

[22] F. P. Incropera, D. P. DeWitt, T. L. Bergman, and A. S. Lavine, Introduction to Heat Transfer (fifth ed.), Wiley, New York (2007).

[23] K. D. Cole, C. M. Tarawneh, and B. M. Wilson, Analysis of flux-base fins for estimation of heat transfer coefficient, Int. J. Heat Mass Transfer. (2008), doi:10.1016/j.ijheatmasstransfer.2008.05.031.

[24] H. S. Carslaw and J. C. Jaeger, Conduction of Heat in Solids (second ed.), Oxford, UK (1959).

[25] K. D. Cole, Green's Function Library, http://www.greensfunction. unl.edu/. 